\title{
Exploring the Academic Literacy Socialization of Mainland China Undergraduates in a Malaysian Tertiary Institution
}

\author{
Radha M. K. Nambiar ${ }^{1} \&$ Noraini Ibrahim ${ }^{1}$ \\ ${ }^{1}$ School of Language Studies and Linguistics, Faculty of Social Sciences and Humanities, Universiti Kebangsaan \\ Malaysia, Selangor, Malaysia \\ Correspondence: Radha M. K Nambiar, School of Language Studies and Linguistics, Faculty of Social Sciences \\ and Humanities, Universiti Kebangsaan Malaysia, 43600 UKM Bangi, Selangor, Malaysia. Tel: 60-389-216-538. \\ E-mail: rads@ukm.my
}

Received: February 7, 2013 Accepted: April 7, $2013 \quad$ Online Published: May 13, 2013

doi:10.5539/ies.v6n6p35

URL: http://dx.doi.org/10.5539/ies.v6n6p35

\begin{abstract}
Internationalization of higher education has witnessed a growing number of students from Southeast Asian countries moving within the region in search of a degree. There is a common tendency among these international students to assume that study will be easier within the region and this has led to issues that need to be addressed. This paper explores one such issue, the academic literacy socialization of mainland China undergraduates in a Malaysian tertiary institution. Specifically this paper will discuss these students' experiences and the literacy practices they employed during a fourteen-week semester doing two reading courses - Academic Reading and Selected Literary Works. Data were collected using background and literacy experience interviews, literacy logs and analytical field notes. The findings suggest while these students think they are prepared to assimilate into the new environment they encounter difficulties and have to negotiate their literacy practices within those of the host country. The paper proposes the need for better preparedness on the part of both study abroad and host country students to enable them to socialize into the new environment and employ appropriate strategies to renegotiate their literacy practices. Teachers should also help these students adjust to their new environment by adapting better inclusive classroom practices.
\end{abstract}

Keywords: academic literacy, academic socialization, tertiary classrooms, international students, literacy practices

\section{Introduction}

Malaysia's tertiary education landscape has seen an increasing number of international students, mainly from countries in the Middle East and more recently China over the last few years. The Ministry of Education's (MoE) 2008 international student statistics reveal as many as 10,355 students from China are enrolled in various private and public higher education institutions. The rise in the number of private institutions of higher learning in Malaysia together with rising costs of study in once popular destinations like the United Kingdom, America, Australia and New Zealand are seen as a major contribution to the changing student demographic in Malaysian tertiary institutions (Findlay \& Tierney 2010; Tierney 2010).

Since 2000, international student mobility in the Asia Pacific region has been growing at a rate of six percent a year compared to only four per cent in the last two decades of the twentieth century (Kim 2008). Southeast Asian countries are also aware of the importance of being proficient and competent in English to be able to exploit international trade and industry. There is therefore a marked increase in the importance awarded to the English language in these countries. There is also an increasing demand for English education and this has led to these countries looking within the region for degree programmes conducted in English. Duff (2010) cautions that because English is viewed as a lingua franca among the Southeast Asian countries, students assume they can participate in study abroad programmes (within the region) without much linguistic difficulty.

Malaysia is seen as an attractive centre of higher education in this region because of the widespread use of the English language in the country (Sharma 2011; Yoshino 2010). Unlike other Southeast Asian countries, English in Malaysia is seen to exist as a second language side by side with Bahasa Melayu, the national language and there are abundant opportunities to learn and use the language here. English is seen as the lingua franca of the business world and with globalization and internationalization of higher education (HE) English has also become 
the medium of instruction for many disciplines.

In a local tertiary institution, the site of this study, students from China come to study for an undergraduate degree in certain faculties like the Faculty of Education, Faculty of Economics and Business which offer their programs in the English language. These learners from mainland China come from an English as a Foreign Language (EFL) background where there is limited or no opportunity to practice English outside the formal domain, the classroom. These learners come from an education system that hinges on grammar-translation methods to learn English with the teacher (usually a native Chinese speaker) being the focal point in the learning process.

The literature is replete with studies pointing to difficulties Asian learners who come to UK, US, Australia and New Zealand face because of their unpreparedness over what to expect. Is it therefore reasonable to assume that participating in study abroad and mobility programmes within the region for students from Southeast Asia will be easier? Can we expect these students to have the appropriate and suitable literacy practices to help them cope during their study abroad experience in Malaysia?

This paper will explore the academic literacy socialization of study abroad China undergraduates in Malaysia by examining the difficulties they experienced and the literacy practices they employed while engaging with reading courses to become members of the Malaysian classroom community.

\section{Literature Review}

Academic socialization in a second or foreign language setting is unique in that learners already have their own academic literacy practices shaped by the linguistic and cultural knowledge of their first language (L1) which they bring to the new setting. These learners have to move from a familiar academic culture to that of the host country and if there are similarities then the interaction and adjustment is easier (Mehdizadeh \& Scott 2005). It is when these learners are thrust into an unfamiliar setting that they will find gaining access and acceptance difficult. Morita (2004)'s study demonstrates how learners experience feelings of insecurity and struggle to understand their new classroom cultures as a result of which they feel incompetent to participate in the class. Research has identified limited proficiency in English, beliefs, cultural values, prior learning experiences, personal traits, conception of learning and motivations as factors that affect Asian students in western contexts (Berno \& Ward 2004).

The fact that these students are able to enter a programme because they have met the language requirement does not guarantee they will succeed in the new academic culture (Bacon 2002; Jepson, Turner \& Calway 2002). Moreover, if the study abroad is for a limited period like one semester there is limited opportunity for adaptation and development. This suggests these learners may need coping strategies to enable them to manage their new cultures. It is hypothesized that to succeed in tertiary learning, students need to be equipped with the literacy practices that will be most meaningful to help them cope with academic demands (Nambiar 2007; Kucer 2005; Casanave 2002).

Research has been comprehensive on how Asian students are adapting to the literacy practices in Western contexts and the findings indicate the challenging and complex nature of academic literacy (Duff 2007; Zamel \& Spack 2004; Seloni 2008; Sasson 2010). Korean students in a Canadian setting preferred to work with other Korean students or Asians and this resulted in a loss of opportunity of practising with native speakers (Duff 2007). Instances of clashes between the host and home countries academic culture was also problematic for many learners who found they had to reset their values and expectations (Zamel \& Spack 2004). Students do not just become a part of the academic community of the classroom but appeared as agents with voices willing to transform the practices surrounding them (Seloni 2008). Ultimately, what is important in such contexts is to recognize the "educational history of the study abroad students who have a rich and diversified system of language aptitude to address literacy events' (Sasson 2010, p. 12-13). Campbell and Li (2009) worked with Asian students in a New Zealand institution and found that while the students were satisfied with their learning experiences in the university they expressed difficulty with the classroom interactions, academic conventions and norms, difficulty in making friends and inability to assimilate into the classroom.

While these findings may reflect the difficulties Asian learners encounter in host countries with Western academic literacy practices, not much is known about how Asian learners cope in other Asian contexts. One study that examined the literacy practices of Asian learners in an Asian context is that of Li (2005). Li examined how a Chinese doctoral student was enculturated into an academic setting at a Chinese university. This study although situated in the student's own country points to the importance of a successful collaborative relationship with the advisor-mentor. Evans and Morrison (2011) tracked the learning experiences and identified challenges of Chinese learners in a university in Hong Kong to understand how they were coping during the first term at the 
university. They found that these students had difficulty comprehending and using specialist vocabulary and understanding the professional academic requirements.

Increasing student mobility within the Southeast Asian region has thrust many learners into new learning environments and cultures. This research intends to highlight that it is erroneous to assume that classrooms and academic culture and practices are the same across the region by investigating how mainland China students are navigating their literacy practices in a Malaysian tertiary classroom.

\section{Theoretical Framework}

Academic literacy in the context of the tertiary institution extends beyond a skills based model of reading and writing to understanding students' experiences and the complexities of their literacy practices. It is about students adapting to other and new ways of knowing which includes understanding, interpreting and organizing knowledge (Lea \& Street 1998, p. 157) Approaches to student literacy in higher education is often viewed in the form of three models ; study skills, academic socialization and academic literacies. The study skills model is concerned with writing skills and literacy and the mechanical aspects of language like grammar and spelling. The assumption is that students can easily transfer this knowledge from one context to another without any problem. The problem with this model is that it overlooks the individuality of learners and what they can already do with their literacy abilities.

The second model, academic socialization, focuses on students' ability to acquire the discourses and practices of a particular discipline or community and presumes that once they have acquired these they are able to adapt to any discipline and community. Lea and Street (2000), do however caution that this approach is based on the premise of a "homogenous culture whose norms and practices have simply be learnt to provide access to the whole institution" (p.35). However, in this era of student mobility, this model is inadequate to sustain the diversity in classrooms and institutions.

The academic literacies model views literacies as social practices and institutions being gatekeepers of academic practices and literacy demands. In this approach, students have to switch practices and adopt varying identities, beliefs and ideologies in their attempts to socialize into the new community. This is different from the academic socialization model, which assumes that students can assimilate into new contexts without having to adopt and adapt to new contexts. While acknowledging that the three models are not exclusive but do overlap, this paper is grounded in the academic literacies approach as study abroad students find they have to adopt new ways of thinking, talking, writing and using language in their host country context (Cumming 2006; Campbell \& Li 2008).

Academic literacies (Lea \& Street 2000) hence, is seen as a range of communicative practices; listening and speaking, reading and writing; common in the tertiary learning classroom that learners will have to participate in to become members of an academic community. How the learners acquire these literacies and how they are socialized into them will increase our understanding of their academic literacy experiences. Using academic literacies as a theoretical lens to examine the difficulties, practices and sources of literacy practices of these mainland China students will shift the focus from the instructor to the learner and help us see the importance of looking at the classroom and its pedagogical structure from the learners' perspectives. As Street (2005) states, there is a "need for unpacking and making explicit what is taken for granted in terms of literacy requirement "(p.6) and this falls on the institution and the lecturers themselves.

\section{Context of Study}

The Malaysian tertiary classroom is dominated by undergraduates from the various ethnic communities prevalent in the country, namely Malays, Chinese, Indians, Sabahans, Sarawakians and others. These students, though of different ethnic origin share similar academic backgrounds as they received their early education from primary or elementary school to secondary or high school in the L1, Bahasa Melayu. English is taught as a second language throughout their primary and secondary education. Hence, most Malaysian students are bilingual and some are even multilingual because of the diverse languages available for study.

Mainland China undergraduates come from varied academic backgrounds and experiences depending on the academic culture of their tertiary institution in China. Most students receive their education in both primary and secondary schools in Mandarin, their L1. English is seen as a foreign language and while the learning of English is seen as important, there are limited opportunities to practice the language. This is so different from Malaysia where there are widespread and ample opportunities to practice the English language.

This study focuses on two reading courses- Academic Reading and Selected Literary Works. Both courses involved reading of expository and literary texts, with the Academic Reading focusing on the reading of journal 
articles, chapters from the course textbook and lecture notes while the Selected Literary Works involved the reading of poems and short stories. The common thread was that for both courses the students were required to read, comprehend and then present their understanding either orally or in written form. This is seen to be the thrust of the academic literacies model and the core of much learning in tertiary education. Hence, the instruments used to collect data centered on their reading, writing, and speaking abilities. The study focused on the academic literacy experiences of two mainland China undergraduates who had registered to do a degree in a Malaysian research university. The trajectory of this study involved understanding the difficulties these learners faced in their new learning environments and what literacy practices they employed in coping with these difficulties.

\section{Methodology}

\subsection{Sampling}

The participants for the study were selected from a group of second year undergraduates who had registered for two courses - Academic Reading and Selected Literary Works. The objective of the research was explained to the class and volunteers were invited to meet with the researcher. The criteria used to select participants were enrollment in the two courses mentioned above, oral proficiency, which was determined from informal conversations, willingness to participate and to allow sessions to be audiotaped. Only two learners, a boy and a girl volunteered to participate in the study and although this may seem like a small sample, the longitudinal approach and the three instruments employed to collect data provided interesting insights into socialization practices in a Malaysian classroom. The two respondents were of the same age, 22, and had similar learning backgrounds in their home country China and were both highly motivated to learn English.

\subsection{Procedure}

A qualitative approach that spanned 1 semester or fourteen weeks was used to collect data in the form of interviews, literacy logs and analytical field notes. Ten interviews were conducted with each learner over the fourteen-week period with the first interview focusing on creating a background literacy profile of each learner. For this first interview, questions were focused on the educational background of each learner (henceforth Eddie and Bella) and included the educational background of the parents and siblings. In addition, the learners were asked to talk about their literacy experiences growing up, the influences from school and home and the nature of the reading and writing assignments they had carried out.

The remaining interviews focused on their current experiences with reading and writing, and specific assignments and how they handled these, the difficulties they faced and the practices they employed. Each interview generally averaged two hours for each learner. The learners also kept reflective literacy logs for each course to document their literacy difficulties, practices and sources of literacy encounters. These were used to inform the interviews and generate questions to clarify matters arising. These logs were used to raise awareness among the learners on the current literacy practices and evaluate these against their own practices. The researcher also maintained field notes during each interview to help inform the transcriptions and identify instances that needed further questioning.

\subsection{Analyses of Data}

The interviews generally lasted for about two hours and each interview was transcribed and examined closely for difficulties in literacy practices. Both the researchers read ad re- read the transcripts and marks were made in the margin of the transcripts to identify difficulties and practices. Then the transcripts were compared and agreement reached on the identification of difficulties and practices. The analyses of data to identify difficulties and practices learners employed are illustrated in Tables 1 and 2 below. 
Table 1. Difficulties in literacy practices

\begin{tabular}{lll}
\hline Teaching Reading ESL & Vocabulary & $\begin{array}{l}\text { Yes. I realise in the past, talk about the first } \\
\text { semester we came here, I find that very difficult } \\
\text { to read a book. A very thick book, like line by } \\
\text { line in English, very difficult. I read one or two } \\
\text { paragraph and so many words I cannot } \\
\text { understand, and now I think read is better in the } \\
\text { literature. }\end{array}$ \\
Selected Literary Works $\quad$ Complex Vocabulary & $\begin{array}{l}\text { While reading the story, the vocabulary is most } \\
\text { difficult thing for us because the word we } \\
\text { know is not enough }\end{array}$ \\
\hline
\end{tabular}

Table 2. Literacy practices employed

\begin{tabular}{ll}
\hline Difficulty with vocabulary & $\begin{array}{l}\text { Ya, most of the time use the dictionary and some of the time... } \\
\text { because dictionary is limited, so I will go searching online. } \\
\text { Some very difficult words that appears frequently, I will } \\
\text { search online and online explanation is very simple. }\end{array}$ \\
\hline
\end{tabular}

The literacy logs and field notes helped to ensure the reliability of the analysis. A co researcher also read and re-read the transcripts to ensure the reliability of the analyses.

\section{Findings}

The findings will examine the literacy profile of the learners, Eddie and Bella, before going on to explore the difficulties and literacy practices they encountered in their new learning environment.

\subsection{Literacy Profile of Eddie}

Eddie was from mainland China and was very proficient in Mandarin, his L1 and fairly proficient in English, a foreign language to him. His parents are considered middle class and he is the only child because of China's one child policy. Both his parents work and his mother was educated until secondary while his father went to a special communist party university and graduated with a degree in economics and business. Eddie received his primary and secondary education in China and came to Malaysia to further his tertiary education. He opted to come here to pursue a Bachelor of Education in the Teaching of English as a Second Language (TESL). Eddie claims "English in China is a foreign language" and "we don't use English to communicate with friends". Since Mandarin is the mother tongue it is assumed that this will be the language of choice among friends for communication and English is only used in situations which necessitate its use which is commonly in classrooms.

English grammar was actually taught formally from secondary school and the focus was on communicative competence. English classes were held daily and lasted for 45 minutes and if a subject teacher failed to turn up they would have more than one class. Language learning was the priority so free periods were divided between Mandarin and English language teachers. Eddie also pointed out that the schools produced their own textbooks and a lot of emphasis was given to grammar and structure. These books were produced locally with the help of foreigners who were employed to help in the teaching of English.

Eddie admits to having weak reading skills so he took two special classes to improve oral proficiency and reading skills. According to him, there are special institutes set up just for English learning. "This school have people who come from English speaking countries. I mean this kind of people may come to China to travel or something, they will stay here for awhile so they are looking for a part time job so they working here to teach the Chinese people". Eddie went to this institute for extra classes because he knew he was going to study in Malaysia and he wanted to improve his language skills. For the oral class they practiced speaking on various topics the teacher provided as a class "a lot of people sitting around and the teacher guide us to discuss some topics". For the reading class he was exposed to intensive reading, extensive reading, a little grammar and even learnt about Malaysian culture. He claimed he was given short articles to read and was asked to identify main points. He likened this to reading a comprehension text and answering short questions.

Activities in the home were centered on the use of the L1, Mandarin. Reading in Mandarin is practiced in his 
home and he has mainly books written in Mandarin at home. He has a few short stories and magazines written in English but states English books are very expensive in China. Eddie is of the opinion that there was no need to speak in English because everyone understood Mandarin so they could speak to each other and still get their message across. He cited himself as an example of someone who only spoke English when he needed to and only with people who could not speak Mandarin.

\subsection{Literacy Profile of Bella}

Bella is also from mainland China and very proficient in Mandarin and the interviews revealed that she speaks better English than Eddie. Bella comes from a middle class family and has an older sister who graduated from a Chinese university. Bella's mother works as a cashier and studied up to secondary school. She obtained her primary and secondary education in China and came to Malaysia to pursue a Bachelor of Education in the Teaching of English as a Second Language (TESL) like Eddie. Bella also claimed that in school, the focus was on grammar and it was an exam-oriented system.

She remembers having to do many exercises from the English textbook, which was then graded by the teacher. Like Eddie's school, her school also produced teaching materials with the help of foreign teachers who were usually either Americans or English. While the focus was on grammar Bella also talked about having to read and answer questions and write essays for examinations. The reading was based on answering questions from a reading text while the writing was very teacher guided. According to Bella, “... the teacher will guide you to write. First, she would guide you to write and tell you what to do and process of writing. Then she will give you a topic and you write by yourself".

As part of the requirement of the degree programme Bella had to do a teaching practicum in an identified school, and she talks about her experiences there and how she realized how different the school experience here was from that in her country. Bella claims that in China students were taught to follow a basic structure when writing, creativity was emphasized when composing their essays. She narrates how she had asked her class of students (during the teaching practicum) to write about a famous person in the world. She found that not only did they all write about Lee Chong Wei, a famous badminton player but they wrote the same things about him. The point she was making was that the element of creativity was missing in the students' essays.

Unlike Eddie, Bella did not go for extra lessons in English because the learning of English was very functional for her as it was only necessary to pass the subject in school. She notes that "In China we learn English just as a subject, however when we come here (Malaysia) we learn English as a tool. A tool, a language tool to learn other subjects." Not having had the extra support in learning English did not seem to be a handicap to her as she claimed she was able to cope with the use of English in her courses as long as she worked hard.

Bella also communicates in Mandarin at home and even though her sister could speak a little English she does not use the language to speak to her. She candidly admits "it's very different to communicate with our relatives in another language because our mother tongue will express all our ideas or feelings fully. However, if we use another language, it seems not familiar, it seems we try to express the meaning not the feeling. So that is the problem". She feels using Mandarin to communicate allows her to express her ideas and feelings much better than using English.

\subsection{Difficulties Encountered in Academic Reading}

Both Eddie and Bella found the new learning environment and the new demands thrust upon them overwhelming. Having come from a traditional and teacher - centered system these learners found themselves having to participate in class activities like group work and presentations. As Bella put it "In China just have to study, remember and produce during examinations" They did not have to worry about oral presentations and group work as it was rote learning that was important. Naturally, for these learners the heavy weightage accorded ongoing assessments $(40-60 \%)$ was very worrisome as their performance in class activities was very important in determining their academic achievement. The learners also found having to work with their peers (who were Malaysian students) challenging as group discussions were in English. Eddie and Bella claimed they were not comfortable speaking in English and hence needed more time to express their ideas but their peers were not willing to wait for them and usually presented their group findings themselves. Upon further probing they admitted they preferred to have their discussions in Mandarin and hence preferred to work with other students from China. .

For the Academic Reading and Selected Literary Works courses, students were assigned different texts or short stories to read which they then discussed in groups before presenting their understanding in the form of an oral presentation or written work. They were left to read and understand the texts independently and this was 
overwhelming for the learners who were used to the teacher guiding them in their reading. Reading of this nature was viewed as taxing and difficult for the learners who struggled to cope with the reading. The task of reading these texts itself was difficult, as they had to struggle with texts in a foreign language and try to comprehend them. This became a time consuming task for these learners and when they also had to present their understanding, they found the task too burdensome and spent many hours on these texts.

A major difficulty for the learners was the lexicon in the reading textbook and in the poems and short stories. The learners found it difficult to read the book as after reading one or two paragraphs they came across many words they were unfamiliar with. This inability to understand the words also meant they spent a long time on the texts and this made the process long and tiresome. Having to constantly look up meanings of unfamiliar words and having to reread parts of the text were cognitively demanding for these learners as they were reading in English. As Bella claims, "in reading the most challenging is the vocabulary". For Eddie problems with the lexicon together with difficulty with sentence structure, grammar and spelling proved to be a main hurdle. Eddie states "We can speak, know the meaning but we cannot spell... vocabulary... weak to follow" He found reading more tedious and the unfamiliar vocabulary and having to read in English made comprehension more cumbersome especially for the literary texts. To quote him "Vocabulary is the most difficult thing for us because the words we know is not enough (to understand the text)"

Both learners in their interviews repeatedly lamented how busy they were and how they had so many tasks to complete and had to work during the weekends and holidays. It is apparent they were taking a long time to read and comprehend the texts and this limitation affected their ability to complete their tasks efficiently. If these learners had worked with Malaysian students, they might have had further assistance in understanding the texts. Instead, they preferred to work with other learners from China as they claimed they could have discussions in Mandarin and this facilitated their understanding of the task. They were of the opinion that trying to have discussions in English took up too much time and effort. In their view as long as they could understand and were able to complete the task, the language used should not be content. Duff (2006) also posits the students in her study were quite content to practice their language ability with each other.

\subsection{Literacy Practices and Sources}

Both the students found the translator a useful tool to deal with unfamiliar lexicon. Bella for instance uses the translator and writes the meaning in Chinese beside the problematic word to enable her to read without stopping to understand the word in English. Bella also uses the online help to search for meanings, "Most of the time use the dictionary and some of the time I go searching online. Online explanation is very simple. Use small words, to explain". Eddie states when he needs help with unfamiliar words he also gets help from friends and the teacher as he feels it is not good to rely too much on the dictionary. He claims ".. its better don't keep looking words in the dictionary, it will interrupt the process of reading". In a way they have got a good approach as they recognize the fastest way to comprehend a text is to just continue reading it and by understanding difficult words in a simple form she is able to do just that. Eddie admitted he found it easier to ask for help from his Malaysian friends as "they were more qualified (meaning more competent)". Both Kobayashi (2003) and Morita (2000) found that seeking help from more experienced classmates and peers was conducive to academic socialization.

Bella also had a very interesting literacy practice which she engaged in after reading texts - she made notes based on what she had understood from the text. She said "... sometimes you can know the ideas but sometimes you cannot understand or you cannot remember it. You cannot transfer their ideas to yours. But when you write again what you have read, that is the way to learn". This a good strategy as by putting into her own words her understanding she was able to display her ability to comprehend the text. This sort of practice needs to be developed with all students to help them gain confidence in expression their understanding of texts they read and will especially help them in paraphrasing.

The two respondents found that over the course of the semester they were able to read the texts without stumbling over unfamiliar vocabulary as they were able to simply guess meaning in context. Bella even said she was now quite good at reading newspapers online, something she never could do in the beginning of the semester. Both learners claimed their vocabulary had expanded with more reading and they were able to understand more words which made their reading more fluent.

\section{Discussion}

The findings of the study do help outline the difficulties these two mainland China undergraduates who registered for a study abroad programme in Malaysia encountered and highlights the specific literacy practices they used when faced with challenges in their new environment. This suggests that even within the Southeast Asian region academic socialization needs to be seen as a complex process which necessitates learners adjusting 
and adapting to new literacy practices. Overall, the findings lead to some important considerations for both the study abroad students and the host country. The students in this study had positive views on the undergraduate programme they were following and over the period of data collection, they appeared to show improved adjustments to the new academic conventions they encountered.

What is apparent is that these students did come with preconceived notions about studying here and they even took steps (as in the case of Eddie) to equip themselves with extra language lessons. They assumed they were moving to a familiar academic culture since it was a move from one Asian country to another and like the learners in Mehdizadeh and Scott (2005)'s study, expected to blend into the new environment easily. Being thrust into a more learning centered environment after having been schooled in a teacher-dominated classroom required them to adjust to the new institutional and academic demands unaided. When faced with the challenges of group work and discussions they chose to work with other students from China and inevitably ended up having their discussions in Mandarin. They find using English to express their ideas difficult and since their aim is to complete the task they resort to their L1. They find their Malaysian counterparts work too slowly or are too pushy and insist their ideas are the best during group work. This is clearly something that needs to be addressed and there needs to be better preparation for host country students to accept and accommodate these study abroad students (Nambiar 2007; Kucer 2005). Familiar with rote learning and regurgitation during examinations and having to now prepare for ongoing assignments, which determined academic achievement, required them to negotiate their literacy practices quickly and cleverly (Zamel and Spack 2004; Seloni 2008). Bella for instance, decided to make short notes of her readings and this she claims helps her to understand what she has read and she is also practicing using her own words to express her understanding of what she has read.

While these students thought they had prepared for their study abroad stint, the findings hint that they lacked knowledge of academic conventions (Campbell and Li 2009). Their need to focus on understanding vocabulary instead of deriving overall comprehension of the texts they read resulted in them spending time uncovering meaning of individual words and not keeping pace with the class. The reality is that like any classroom academic rules and conventions are implicit, and the student is expected to understand them and adapt to them to be able to function effectively. If in the Western classroom, the Asian student is forced to take responsibility for learning and learn the cultural norms and conventions, the same responsibility has to be visible in another Asian context. Perhaps these study abroad students need to be introduced to academic discourses in the host country, in this case Malaysia. Campbell and Li (2009) posit "The onus is placed on international students to adopt to the host learning contexts where they are studying" (p. 390).

Nevertheless, Malaysian lecturers need to help these study abroad students adapt to the new classroom culture and help them adjust to the new demands and notions of teaching and learning. As Sasson (2010) reminds us it is important to consider whether the study abroad experience has been valuable to the student and looking at what literacy practices these students bring with them and how they negotiate and adjust these to the new practices will help us understand the gains for the students. In the context of this study then it is important to recognize what strategies these students are already using to help them make sense of texts and use this knowledge to help them negotiate the new strategies they encounter in the host country.

The findings are representative of these two students from mainland China and may not be generalizable because of the small sample used in the study. It is also necessary to remember that linguistic and cultural variations can in turn result in different personal and educational backgrounds. It will be interesting to see if there are definite patterns and trends with a larger sample perhaps using a survey method. A comparison of international students from different countries with Malaysian students may also reveal academic socialization as a more multidimensional sociocultural process

\section{Conclusion}

The findings provide insights into the pedagogical practices in Malaysian classrooms to help international students negotiate their academic socialization practices. By exploring their literacy experiences the study has revealed that knowing about the process of socialization helps us to understand these learners better. Instructors must examine their own instructional practices to see if they are accommodating these learners. For instance since the lexicon is a major difficulty measures must be taken to ensure lexicon development is included in the courses. Instructors in higher education institutions need to be more cognizant of the dynamics of their classrooms especially when there are international students to ensure these students are encouraged to participate in classroom discussions. Whenever possible these international students need to be paired with a local student in pair work or in group work to ensure they are not made to feel marginalized because of their language proficiency. 
It is important to be cognizant of the fact that reading is a primary form of academic literacy and learners must have effective instruction in it to enable them to be successful in tertiary education. Learners who are unfamiliar with the importance of being able to read effectively and efficiently need to be taught how to approach texts to maximize their literacy experiences. These learners should be encouraged to seek opportunities to practice their literacy practices with learners from the host country (Duff 2007) so as to minimize conflict with the prevailing literacy practices (Morita 2009; Leibowitz 2005; Zamel \& Spack 2004 ).

\section{References}

Bacon, S. (2002). Learning the rules: Language development and cultural adjustment during study abroad. Foreign Language Annals, 35(6), 637-646. http://dx.doi.org/10.1111/j.1944-9720.2002.tb01902.x

Berno, T., \& Ward, C. (2004). Cross cultural and educational adaptation of Asian students in New Zealand. Research report for Asia: NZ Foundation. Retrieved April 20, 2011, from http://www.asianz.org.nz/files/wardbernoreport.pdf

Campbell, J., \& Li, M. (2008). Asian Students' Voices: An Empirical Study of Asian Students' Learning Experiences at a New Zealand University. Journal of Studies in International Education, 12(4), 375-396. http://dx.doi.org/10.1177/1028315307299422

Casanave, C. P. (2002). Writing games: Multicultural case studies of academic literacy practices in higher education. Mahwah, NJ: Lawrence Erlbaum.

Cumming, A. (2006). Introduction, purpose, and conceptual foundations. In A. Cumming (Ed.), Goals for academic writing ESL students and their instructors (pp. 1-18). Philadelphia, PA: John Benjamins Publishing Company.

Duff, P. (2007). Problematizing academic discourse socialization. In H. Marriott, T. Moore, R. Spence-Brown, \& R. Melbourne (Eds.), Learning discourses and the discourses of learning (pp. 1-18). Monash University e-Press/University of Sydney Press.

Duff, P. (2010). Language socialization into academic discourse communities. Annual Review of Applied Linguistics, 30, 169-192. http://dx.doi.org/10.1017/S0267190510000048

Duff, P. A. (2006). Problematizing language socialization across post secondary contexts. Paper presented at the joint conference of AAAL and ACLA, Montreal, Quebec, Canada.

Evans, S., \& Morrison, B. (2011). The first term at university: Implications for EAP. ELT Journal, 65(4), 387-397. http://dx.doi.org/10.1093/elt/ccq072

Findlay, C., \& Tierney, W. (2010) Globalisation and tertiary education in the Asia-Pacific - The Changing Nature of a Dynamic Market. World Scientific Publishing Company.

Jepson, M., Turner, T., \& Calway, B. (2002). The transition of international students into the postgraduate study: An incremental approach. Australian Association for Research in Education (AARE), International Education Research Conference Brisbane December 1-5, 2002. Retrieved April 20, 2011, from http://www.aare.edu.au/02pap/tur02193.htm

Kim, Y. C. (2008). The Asia-Pacific education market and modes of supply. In C. Findlay, \& W. G. Tierney (Eds.), The Globalization of Education: The next Wave. World Scientific Publishing Company: Singapore.

Kobayashi, M. (2003). The role of peer support in ESL students' accomplishment of oral academic tasks. Canadian Modern Language Review, 59, 337-368. http://dx.doi.org/10.3138/cmlr.59.3.337

Kucer, S. B. (2005). Dimensions of Literacy: A conceptual base for teaching reading and writing in school settings (2nd ed.). Mahwah, NJ: Lawrence Erlbaum.

Lea, M., \& Street, B. V. (1998). Student Writing and Staff Feedback in Higher Education: An Academic Literacies Approach. Studies in Higher Education, 23(2), 157-72. http://dx.doi.org/10.1080/03075079812331380364

Lea, M. R., \& Street, B. V. (2000). Student writing and staff feedback in higher education: New contexts. Buckingham. The Society for Research in Higher Education and Open University.

Leibowitz, B. (2005). Learning in an additional language in a multilingual society: A South African case study on university-level writing. TESOL Quarterly, 39, 661-681. http://dx.doi.org/10.2307/3588526

Li, M. (2005). Communicating effectively with Chinese students in EFL/ESL classrooms. In P. Robertson, P. Dash, \& J. Jung (Eds.), English language learning in Asian context (pp. 75-100). Pusan, South Korea, Asian 
EFL Journal Press.

Mehdizadeh, N., \& Scott, G. (2005). Adjustment problems of Iranian international Students in Scotland. International Education Journal, 6, 484-493.

Morita, N. (2000). Discourse socialization through oral classroom activities in a TESL graduate program. TESOL Quarterly, 34, 279-310.

Morita, N. (2004). Negotiating participation and identity in second language academic communities. TESOL Quarterly, 38, 573-603

Morita, N. (2009). Language, culture, gender, and academic socialization. Language and Education, 23, 443-460.

Nambiar, R. M. K. (2007). Learning realities of the academically literate learners. In H. Azman, Lee, K. S., \& Noorizah Mohd Noor (Eds.), Transforming learning realities in the ELT world (pp 90-97). Pearson Longman, Kuala Lumpur.

Sasson, A. (2010). Literacy Experiences and Cultural negotiations in transnational academic contexts: The case of Israeli study abroad MBA students in an American university. Unpublished PhD Dissertation. Indiana University of Pennsylvania, Pennsylvania.

Seloni, L. (2008). Reconceptualization of academic literacy socialization in an intercultural space: A micro-ethnographic inquiry of first year multilingual doctoral students in the U.S. Unpublished $\mathrm{PhD}$ Dissertation. State University of Ohio, USA

Sharma, Y. (2011). ASIA: Countries vying to become education hubs. Retrieved October 20, 2011, from http://www.universityworldnews.com/article.php?story=20110318130607540

Street, B.V. (2005). Literacies across educational contexts. Mediating learning and teaching.

Tierney, W. (2010). Forms of privatization, In Christopher Findlay, \& William Tierney (Eds), The Globalisation of Education: the Next Wave (pp. 163 -200). World Scientific Publishing Company.

Yoshino, K. (2010). The Englishization of Higher Education in Asia and Migratory Flows of International $\begin{array}{lllll}\text { Students. } & \text { Retrieved } & \text { October } & 20, & \text { 2011, }\end{array}$ http://www.policyinnovations.org/ideas/commentary/data/000169

Zamel, V., \& Spack, R. (Eds.). (2004). Crossing the curriculum: Multilingual learners in college classrooms. Mahwah, NJ: Lawrence Erlbaum. 